\title{
Safety climate perceptions and attitudes of supervisors in the Korean Industry
}

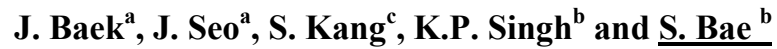 \\ ${ }^{a}$ ChungJu National University, Department of Safety Engineering \\ ${ }^{b}$ University of North Texas Health Science Center, Department of Biostatistics \\ ${ }^{\mathrm{c}}$ Yeungnam University, Department of Statistics \\ Email: Sejong.bae@unthsc.edu
}

\begin{abstract}
Over the past 20 years in Korea, the incidence rate of industry accidents has been steadily decreasing from $2.66 \%$ in 1987 down to $0.99 \%$ in 1995 . This reduction may be due to the proper management of hazardous machinery, Process Safety Management, Clean 3D Project, KOSHA18001 certification and more effective, technical and systematic approaches on safety. In 1998, the incidence rate was decreased to $0.68 \%$ and has remained at that rate for the last 13 years. This may be due to the various external industry environment changes. In particular, the disasters caused by unsafe behaviors are about $80 \%$ of the incidences. This criterion may need the attention and commitment of managers and administrators more than anything else at this time. Supervisors, usually at the forefront, have had direct involvement in injury accident prevention. We investigated the safety climate perceptions and attitudes of the supervisors. 1,507 sites out of total 11,883 worksites' random proportional samples were chosen based on industry type, size strata. On a five point scale questionnaire, 42 items were developed through expert advisory committee meetings. Safety and health awareness perceptions and attitude scores were calculated. Reverse coding was used for the negative questions asked. Supervisors' perceptions and attitudes on safety and health awareness had a mean of 3.61, and a standard deviation of 0.713 , respectively. In particular, this number varied by the size of business, the age, gender, and longevity at the current work.
\end{abstract}

Keywords: Industry accident rate, Safety, Survey 


\section{INTRODUCTION}

Over the past 20 years in Korea, the incidence rate of industry accidents had been steadily decreasing from $2.66 \%$ in 1987 down to $0.99 \%$ in 1995 (Figure 1). This reduction may be due to the proper management of hazardous machinery, Process Safety Management, Clean 3D Project, KOSHA18001 certification and more effective, technical and systematic approaches on safety. In 1998, however, the incidence rate was decreased to $0.68 \%$ and has remained at that rate for the last 13 years. This may be due to the various external industry environment changes. In particular, the disasters caused by unsafe behavior partake about $80 \%$ of the incidences. This criterion may need the attention and commitment of managers and administrators more than anything else at this time. Supervisors that are usually at the forefront have had direct involvement in injury accident prevention.

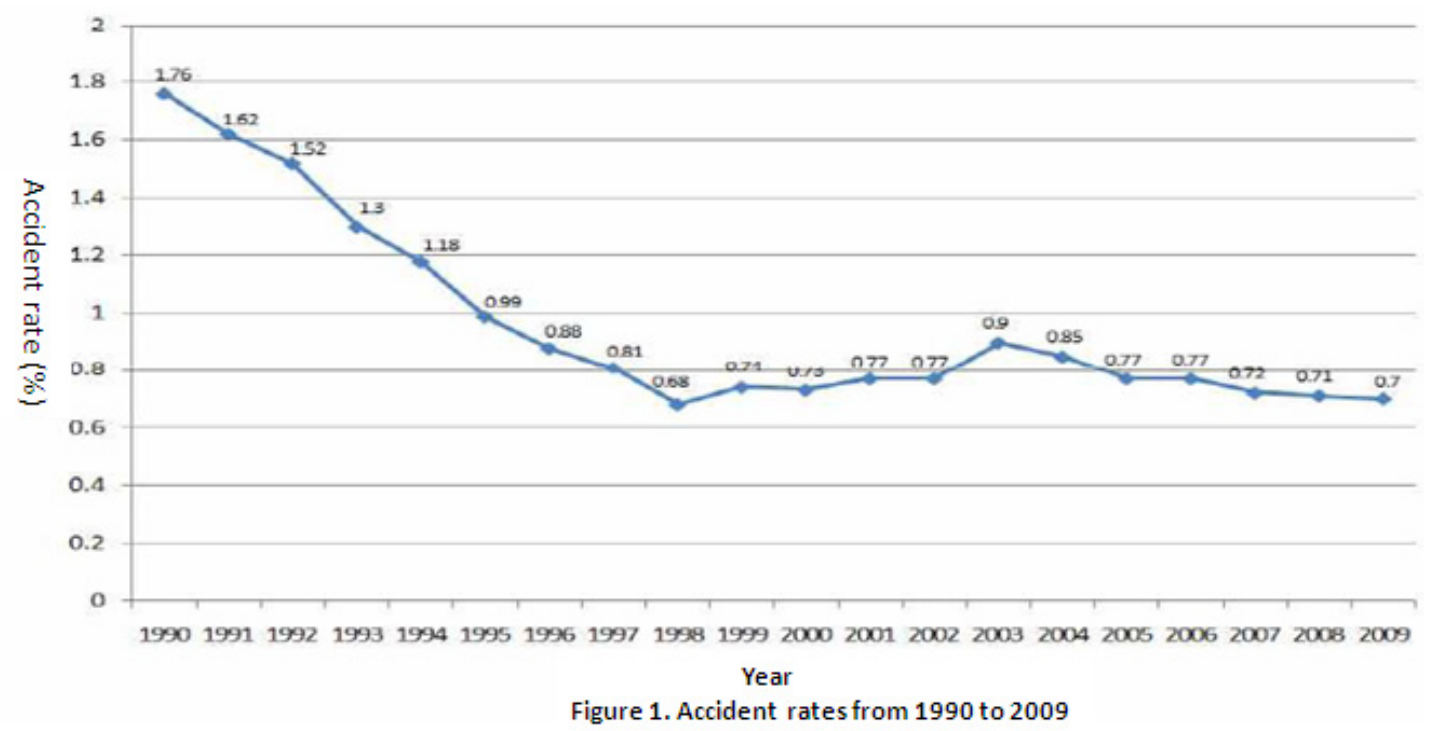

The safety climate has been recently recognized as a fundamental and ultimate solution for improving workplace safety in various industries, including manufacturing industries such as chemical plants. Lord Cullen (1990) emphasized, during the Piper Alpha inquiry, that it is essential to create a corporate atmosphere or culture in which safety is understood to be, and is accepted as, the number one priority. Fennell (1988) stated that, following the Kings Cross fire, a cultural change in management is required throughout the organization. Petersen (1996) demonstrated that culture is to a large degree behind humancaused catastrophes. Zebroski (1991) found eleven attributes which have had medium to large degrees of commonality in the basis for the TMI-2, Chernobyl, Challenger, and Bhopal events.

There have been attempts to improve the safety culture and climate among industries as well as government agencies in Korea. However, there is a limited number of safety climate studies done in Korean manufacturing industries. We investigated the safety climate perceptions and attitudes of the supervisors. 1,507 sites out of total 11,883 worksites' random proportional samples were chosen based on industry type, size strata. On a five point scale questionnaire, 42 items were developed through expert advisory committee meetings. Safety and health awareness perceptions and attitude scores were calculated. Reverse coding was used for the negative questions asked.

\section{METHODS}

\subsection{Data}

We investigated the safety climate perceptions and attitudes of the supervisors. Random proportional samples were chosen based on industry type, size, and location. One thousand five hundred and seven sites out of total 11,883 worksites were selected. The research team developed a five point scale questionnaire with 42 items on it, and supplemented these through expert advisory committee meetings. Safety and health 
awareness factors, perceptions, and attitude scores were calculated. Reverse coding was used for the negative questions asked.

\subsection{Analysis}

Analysis of the data was done using SPSS version 18.0. Descriptive statistics and further analysis were carried out. Significance level was set at alpha level of 0.05 . The final measures contained 42 items in nine dimensions. Internal consistency reliability coefficients (Cronbach's alpha) for the factors were all greater than 0.735 (Table 1).

Nine dimensions of the safety climate in Korean industries were identified:

F1: Efforts in enforcing both safety and health standards

F2: Management safety and health commitment

F3: Safety communications;

F4: Safety and Health Education

F5: Employees' safety behaviors and perception towards hazardous jobs

F6: Work Pressure

F7: Initiation of acquiring knowledge in safety and health

F8: Promoting importance of safety and health

F9: Compliance

Table 1. Dimension Means and reliability coefficients

\begin{tabular}{|l|l|l|l|}
\hline Dimension & $\begin{array}{l}\text { Number } \\
\text { of items }\end{array}$ & Mean & $\begin{array}{l}\text { Cronbach } \\
\text { Alpha }\end{array}$ \\
\hline F1: Efforts to enforce safety and health standards & 6 & 3.36 & 0.735 \\
\hline F2: Management safety and health commitment & 6 & 3.70 & 0.870 \\
\hline F3: Safety communications; & 5 & 3.55 & 0.893 \\
\hline F4: Safety and Health Education & 4 & 3.49 & 0.890 \\
\hline $\begin{array}{l}\text { F5: Employees' safety behaviors and perception toward } \\
\text { hazardous jobs }\end{array}$ & 4 & 3.64 & 0.883 \\
\hline F6: Work Pressure & 5 & 3.62 & 0.914 \\
\hline $\begin{array}{l}\text { F7: Initiation of acquiring knowledge in safety and } \\
\text { health }\end{array}$ & 4 & 3.98 & 0.873 \\
\hline F8: Promoting importance of safety and health & 4 & 3.63 & 0.893 \\
\hline F9: Compliance & 4 & 3.59 & 0.900 \\
\hline
\end{tabular}

\section{RESULTS}

Supervisors' perceptions and attitudes on safety and health awareness had an overall mean of 3.61, and a standard deviation of 0.713 , respectively. Initiation of acquiring knowledge in safety and health had the highest score (3.98) and efforts to enforce the safety and health standards had the lowest (3.36) (Figure 2). In addition, these scores varied by the size of business, age, gender, and longevity at the current work (see table 2 ). Gender differences were statistically significant for all the factors $(\mathrm{P}<0.05)$. Male had higher dimension scores across most of the safety and health dimension, except the safety and health education. 
Baek et al., Safety climate perceptions and attitudes of supervisors in Korean Industry

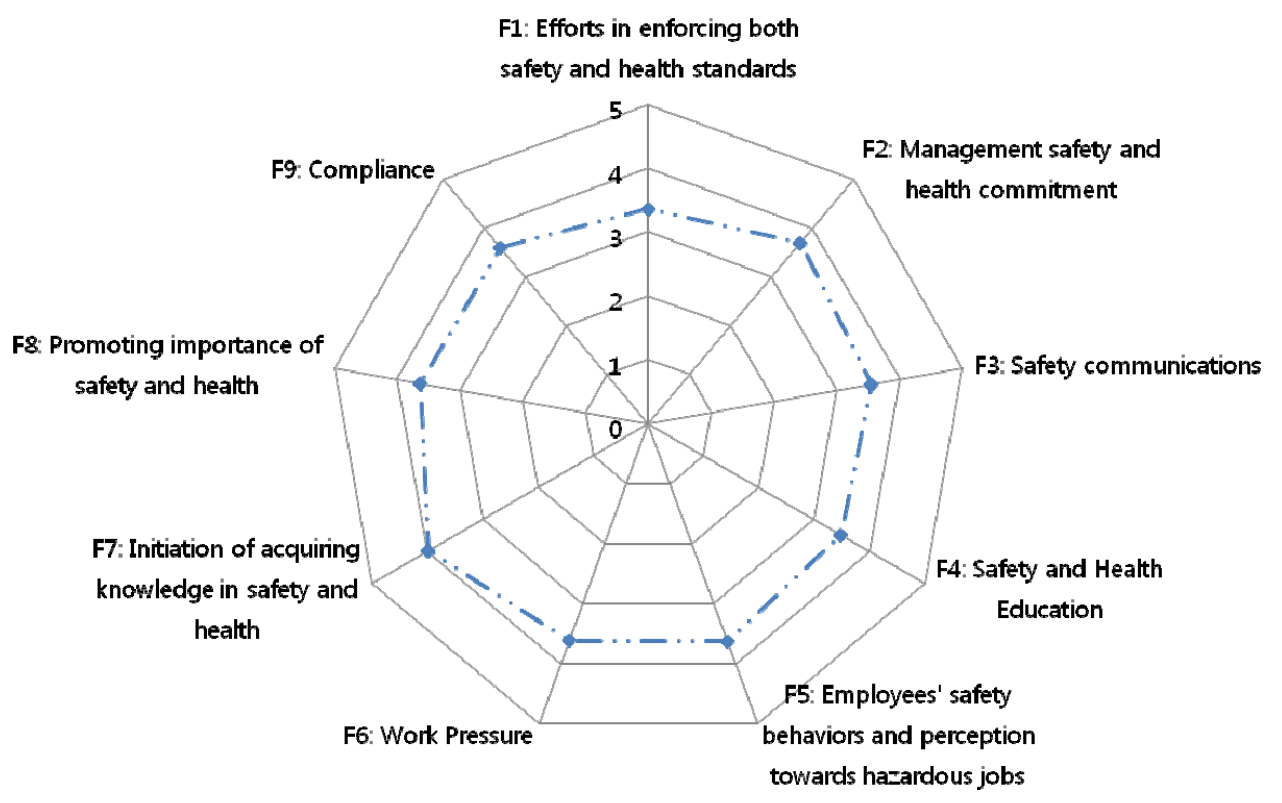

Figure 2. Safety climate factor scores

Table 2. Means of safety climate dimensions between gender

\begin{tabular}{|l|l|l|l|}
\hline Dimension & Male & Female & p-value \\
\hline Efforts to enforce safety and health standards & 3.37 & 3.16 & $<0.001$ \\
\hline Management safety and health commitment & 3.72 & 3.47 & 0.003 \\
\hline Safety communications; & 3.57 & 3.37 & 0.016 \\
\hline Employees' safety behaviors and perception toward hazardous job & 3.66 & 3.45 & 0.005 \\
\hline Work Pressure & 3.65 & 3.30 & $<0.001$ \\
\hline Initiation of changes in safety and health & 4.00 & 3.74 & 0.008 \\
\hline Initiation of changes in a safer work environment & 3.65 & 3.43 & 0.012 \\
\hline Compliance & 3.61 & 3.40 & 0.005 \\
\hline
\end{tabular}

In general, older age group had higher dimension scores across most of the safety and health dimension except the safety and health education and employees' safety behaviors and perception toward hazardous job (table 3).

Table 3. Means of safety climate dimensions by age group

\begin{tabular}{|l|l|l|l|l|l|l|}
\hline & \multicolumn{5}{|c|}{ Age group } & \\
\hline Dimension & $20-29$ & $30-39$ & $40-49$ & $50-59$ & $60+$ & p-value \\
\hline Efforts to enforce safety and health standards & 3.11 & 3.35 & 3.37 & 3.39 & 3.45 & 0.011 \\
\hline Management safety and health commitment & 3.42 & 3.67 & 3.71 & 3.80 & 3.79 & 0.003 \\
\hline Safety communications; & 3.24 & 3.55 & 3.55 & 3.63 & 3.69 & 0.002 \\
\hline Initiation of changes in safety and health & 3.25 & 3.60 & 3.64 & 3.76 & 3.65 & $<0.001$ \\
\hline Initiation of changes in a safer work environment & 3.29 & 3.55 & 3.62 & 3.70 & 3.67 & 0.001 \\
\hline Compliance & 3.32 & 3.60 & 3.64 & 3.76 & 3.65 & 0.001 \\
\hline
\end{tabular}




\section{DISCUSSION AND CONCLUSIONS}

The purpose of this study was to explore the levels of the safety climates in Korean industry. Especially the targeted plants proportion to size, location, and types of industry. So these industries meet with the preconditions for measuring safety climates suggested by HSE (HSE, 1999, 2000, 2002). 'F7: Initiation of acquiring knowledge in safety and health' was the highest among supervisors and ' $F 1$ : Efforts to enforce safety and health standard' was recorded as the lowest. Males showed higher scores across most of the domain, and older supervisors had higher scores. These results are a little different to the results from Correll (2000, 2001). In this study, plant size (number of employees) had a significant relationship to the level of the safety climate, in contrast to Correll (2001). The levels of safety climate showed an upside-down U-type distribution (Low-High-Low) by age group. Thus, it would be beneficial to have a regular and systematic continuing education and training for employees in order to reinforce safety in the workplace by each different age group and female workers.

\section{REFERENCES}

Correll M and Andrewartha G, Positive Safer Culture: the key to a safer meat industry, 2000.

Correll M and Andrewartha G, Meat Industry Survey of OHS Culture, 2001.

Cullen WD, The public inquiry into the Piper Alpha Disaster, Department of Energy: HMSO, 1990.

Fennell, D. Investigation into Kings Cross Underground Fire. Department of Transport, HMSO, 1988,

Health and Safety Executive (HSE), Summary Guide to Safety Climate. HSE, HSE Books, 1999.

Health and Safety Executive (HSE), Safety culture maturity model. HSE, HSE Books, 2000.

Health and Safety Laboratory (HSL), Safety Culture: A review of the literature. HSL Human Factors Group, 2002.

Petersen Dan, Human error reduction \& safety management, 3rd edition International Thomson Publishing, 1996 ,

Zebroski, E., Lessons Learned from Man-made Catastrophes, in Risk Management, New York: Hemisphere Publishing, 1991. 